Research Article

\title{
Effects of Excavation Gap Filling of Under-1 Crossing Tunnel on Pipelines
}

\author{
Hua Jiang $(\mathbb{D}$, Longfei Chang, Jingling Zhang, and Pinglin Jiang 10 \\ School of Mechanics and Civil Engineering, China University of Mining and Technology, Beijing 100083, China \\ Correspondence should be addressed to Hua Jiang; jianghua@cumtb.edu.cn
}

Received 4 May 2021; Revised 20 October 2021; Accepted 25 November 2021; Published 14 December 2021

Academic Editor: Pengfei Wang

Copyright (c) 2021 Hua Jiang et al. This is an open access article distributed under the Creative Commons Attribution License, which permits unrestricted use, distribution, and reproduction in any medium, provided the original work is properly cited.

\begin{abstract}
Excavation gap filling is an important means to control the strata movement in tunneling. In practice, synchronous grouting or secondary replenishment of the gap is usually used to control the settlement, instead of filling the excavation clearance. In fact, the diameter of the cutterhead is usually slightly larger than that of the shield, and the front shield is also larger than its back. As a result, there will be an annular gap (i.e., an excavation clearance) between the tunnel soil layer and the shield. Thus, effectively filling the gap contributes to controlling the formation displacement. In this paper, the Wei Lai Da Dao to Feng Tai Nan Lu section of Zhengzhou Metro Line 3 is selected as the study object. Based on the three-dimensional finite element method, the influence of an under-crossing shield tunnel sewage pipes on strata movement under complicated conditions is analyzed. Field tests also show that the movement and development trend are similar to the simulated results, which further indicates that, under similar geological conditions, numerical simulation results can be used to guide the filling of excavation clearance in EPB. It is found that the excavation gap filling can effectively reduce the surface settlement rate and make the surface settlement stabilize faster and the curve shape of "settlement trough" changes from "narrow and deep" to "shallow and wide." However, the grout used in this method should be with the properties of short hardening time, large elastic modulus, and low shear strength. Besides, the excavation gap filling can also reduce the extrusion deformation of sewage pipe and inhibit the horizontal and vertical displacement of sewage pipes. Therefore, it is considered that excavation clearance filling is an effective method to reduce stratum movement and tunnel deformation, which is of great significance for future research and practical engineering.
\end{abstract}

\section{Introduction}

Shield tunnel boring machine construction is one of the most widely used methods in tunnel construction. Its stability and rapidity make it the main technology for the construction of subway tunnels. The optimization of the impact of shield construction on surrounding buildings and the reduction of ground deformation have become the main problems in shield construction. With the rapid development of urban rail transit, the underground space resources are becoming increasingly tight, and the net distance between new subway tunnels and existing buildings is getting smaller and smaller. Many new subway tunnels are inevitable to go through underground, on top, or parallel to the existing tunnels, underground pipelines, or pile foundations of buildings. Therefore, the study on the control of ground displacement plays an important role in the stability of underground buildings and pipelines [1-5]. In the shield construction process, soil stress release caused by the cutting effect of the cutter disc and the gap generated in the shield construction have an adverse impact on the stratum stability, surrounding buildings, and underground pipelines [6-11].

The supporting pressure of the workface and the shield tail simultaneous grouting can reduce the formation loss to a certain extent $[12,13]$. In the research process, more people focus on the grouting problem, and they usually use model test, numerical simulation, field measurement, analytical method, and other methods to conduct research [14-19]. Xie et al. [20] summarized the numerical prediction, and field test data show that grouting pressure and quality appear to determine the surface settlement rather than the supporting pressure at the workface. Michael et al. [21] simulated the 
process of shield excavation by finite element software, including overexcavation of cutterhead, lining assembly, circumferential grouting, and grouting hardening. Based on the finite element analysis, Sharghi et al. [22] compared the results of experimental parameters with numerical simulation to study the influence of material parameters on surface settlement. Based on monitored data, Jin et al. [23] proposed that the in-tunnel grouting protection method could greatly reduce the effect on the existing tunnels when twin tunnels were built underneath. Based on numerical simulation and actual measurement research, Yin et al. [24] found that timely neutral grouting was an effective method to control the settlement caused by the excavation gap, and the linear regression method was used to obtain the relationship between settlement and elastic modulus. Rowe et al. [25] applied gap parameters to predict the settlement of the surface and the stratum and defined them as the equivalent two-dimensional gap set formed around the tunnel. The ground loss rate ranges from 0 to $0.4 \%$ based on different shield construction methods and excavated strata.

Most of the above studies focus on the effect of shield tail grouting on the stability of the formation. However, due to the geometry and working principle of the shield, a ringshaped excavation gap of $20 \sim 30 \mathrm{~mm}$ would form between the cutterhead and the surrounding rock, and simultaneous grouting can effectively fill the gap of the shield tail, so the settlement caused by the excavation gap is also worthy of attention. In the actual construction process, as shown in Figure 1, the shield tail clearance and the excavation gap in the back shield are larger than that in the front shield. The gaps are above the shield, and the corresponding formation loss is about $0.3 \% \sim 0.8 \%$. When the soil above the shield machine is not stable enough, without grouting, the soil above the shield will fill the entire excavation gap, further causing a large movement of the upper strata and a large settlement of the surface.

The author finds that studies on the filling excavation gap both at home and abroad have been rarely reported. The excavation gap and the postwall grouting have a significant influence on the settlement of the stratum. It is hard to study distortion and displacement through measuring points on tunnels. In this paper, numerical simulation was used to fine simulate the gap parameters of the shield. Based on the measured data of the surface settlement of Weilai Da Dao to Fengtai South Road section of Zhengzhou Rail Line 3 (hereafter referred to as the "Wei Feng" section), the influence of filling excavation gap on the displacement of the surface and sewage pipe was analyzed, and the effect of tunneling on the distribution of lateral and longitudinal displacement fields of the surrounding soil was studied.

\section{Engineering Conditions and Filling Materials}

2.1. Geological Profile. The tunnel stratum in the Wei Feng section belongs to the Quaternary Holocene alluvium layer, which mainly consists of artificial soil, silty soil, silty clay, silty sand, and fine sand from top to bottom. During the site survey of the Wei Feng section, the burial depth of the stable water table is between 5.71 and $5.74 \mathrm{~m}$, and the water

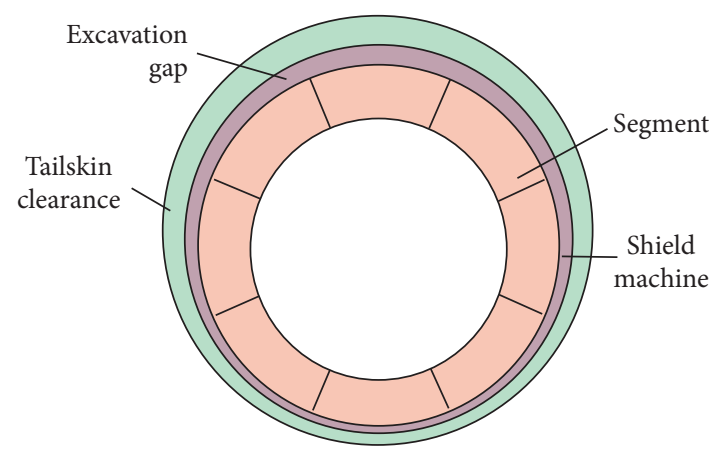

Figure 1: Actual shield clearance.

level elevation is about 87.06 to $7.78 \mathrm{~m}$. The water in this layer is stored in silty soil and sand layer of alluvium below the water level. The preceding tunnel of the section is $450.969 \mathrm{~m}$ long, and the succeeding tunnel is $450.318 \mathrm{~m}$ long, mainly buried in silty clay and organic silty clay (the plan view of tunnels is shown in Figure 2). The geological longitudinal and transverse sections are shown in Figures 3 and 4 . The tunnel line is often side-by-side or intersects with the old sewage main pipes. The minimum distance between the tunnel and the pipe is about $3.5 \mathrm{~m}$. During the crossing, the sewage pipe fittings may rupture, giving off a large amount of sewage and affecting the surrounding environment.

2.2. Filling Materials. In tunneling, as the cutterhead approaches the observation section, the ground surface uplifts due to the pressure of the Earth chamber, and the deep soil moves away from the tunnel. The rotating cutting wheel and the soil displacement of the screw conveyor make the soil around the shield move toward the excavation gap, and then the pressure gradually transmits to the surface in the formation, causing uneven settlement of the formation and rupture of the sewage pipe fittings. Therefore, at the $100^{\text {th }}$ to $120^{\text {th }}$ rings of the right line tunnel, the excavation gap is filled through the grouting hole at 1 and 12 o'clock directions of the front shield.

The filling material is composed of bentonite, water glass, and water, whose viscosity reaches $300 \sim 500 \mathrm{dPa}$.s. The filling material is divided into liquid $\mathrm{A}$ and liquid $\mathrm{B}$. The ratio of liquid $\mathrm{A}$ is bentonite: water $=1: 2$, and the ratio of liquid $\mathrm{B}$ is sodium silicate: water $=1: 1$. After the mixture of liquid $A$ and liquid $\mathrm{B}$, the ratio of liquid $\mathrm{B}$ to the volume is controlled at $5 \%$ to $6 \%$. High elastoplasticity of the filling material avoids seizing up the shield and increases the frictional resistance, and its initial setting time is within 40s so that the filling area is predictable. Tunneling $1.5 \mathrm{~m}$ will theoretically produce an excavation gap of $0.5 \mathrm{~m}^{3}$. Therefore, taking account of the coefficient of $200 \%$ of the theoretical value, each ring requires filling $1 \mathrm{~m}^{3}$ material to control the settlement.

\section{Numerical Modeling}

3.1. Numerical Model Parameter. The ABAQUS (2016) finite element simulation software was used to determine the three-axis direction by the Cartesian coordinate system. The 


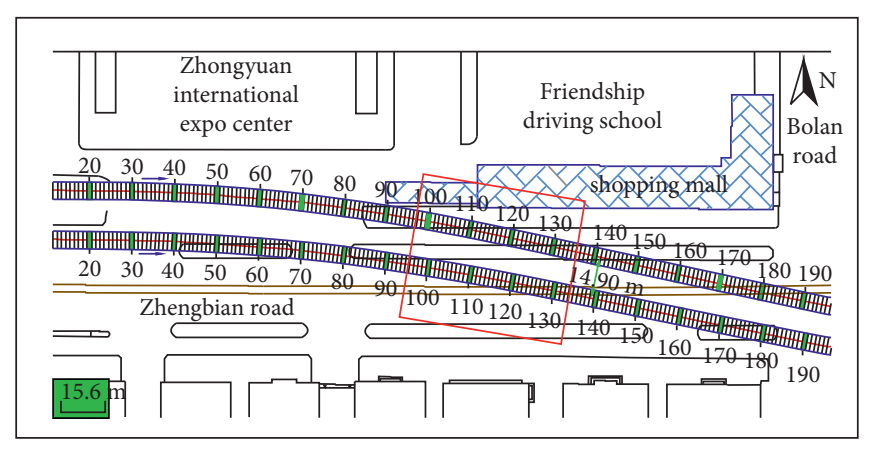

(a)

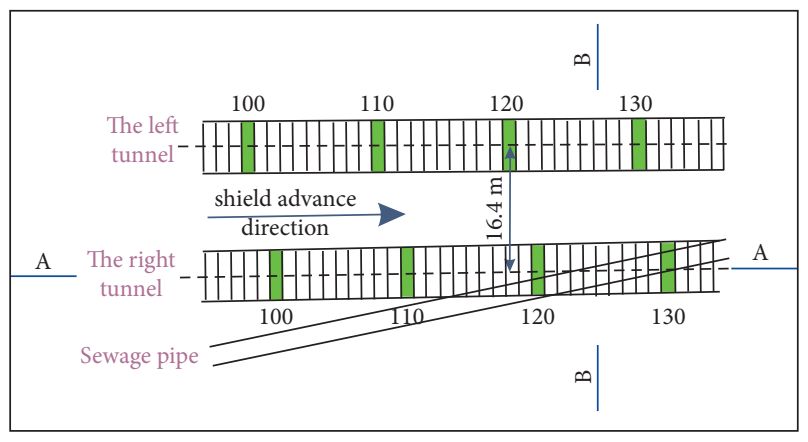

(b)

Figure 2: Shield line detail.

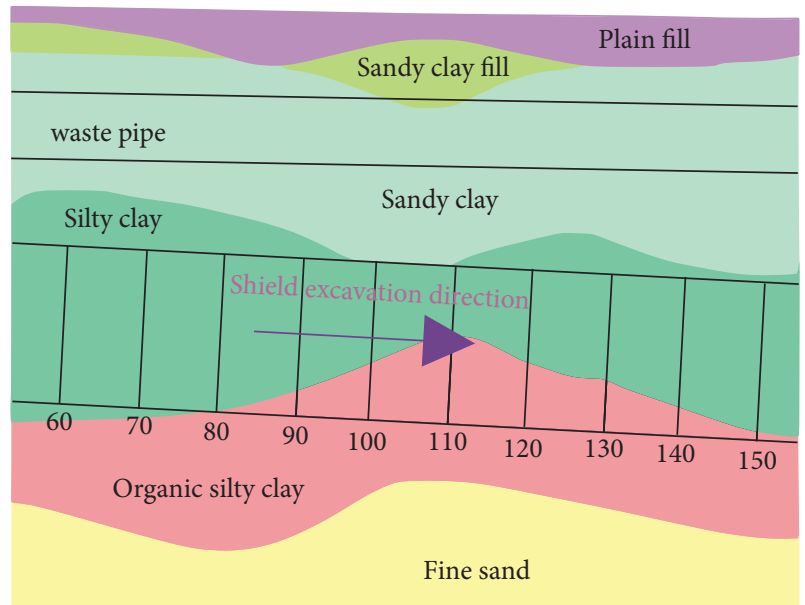

Figure 3: A-A section.

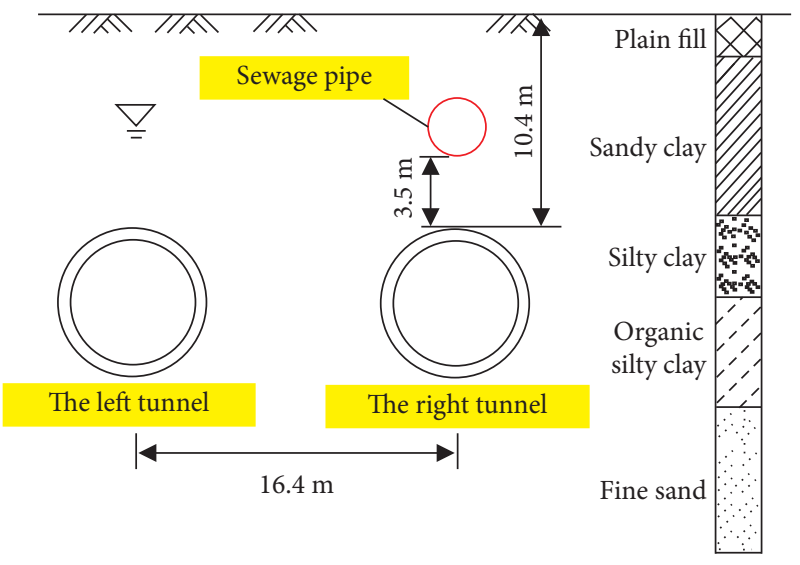

Figure 4: B-B section.

model size was $70 \mathrm{~m}(X$ direction $) \times 40 \mathrm{~m}(Y$ direction $) \times$ $75 \mathrm{~m}$ ( $Z$ direction), and the sewage pipe was parallel to the tunnel. The positional relationship of the tubes is shown in Figure 5 . The side is limited to the horizontal displacement and the corner, the bottom surface is fully fixed, and the top surface is freely constrained. The surface of the groundwater level line is set as the seepage boundary. The pore water pressure is zero, and the side and bottom surfaces are

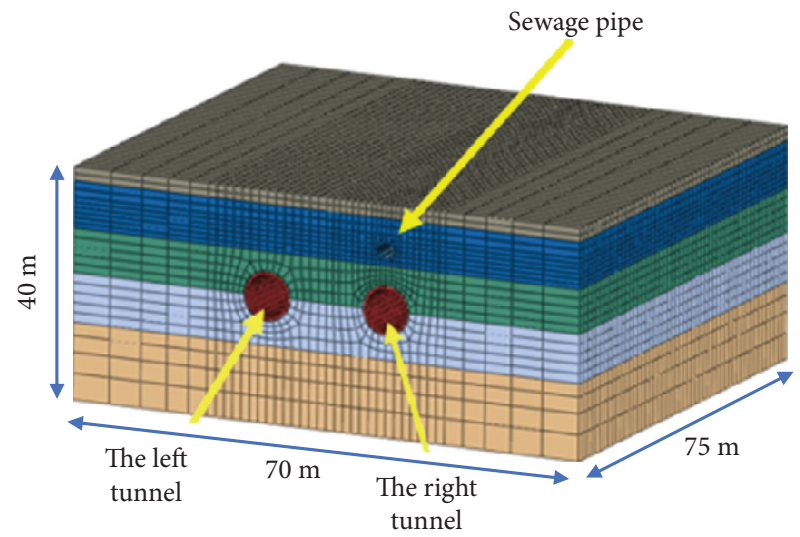

Figure 5: Dimensions and meshing of the model.

impervious. The diameter of the shield is $6.48 \mathrm{~m}$, the front shield diameter is $6.45 \mathrm{~m}$, the outer diameter of the segment is $6.2 \mathrm{~m}$, the inner diameter is $5.5 \mathrm{~m}$, the width of the segment is $1.5 \mathrm{~m}$, the thickness of the segment is $0.35 \mathrm{~m}$, the thickness of the shield is $0.04 \mathrm{~m}$, and the thickness of the excavation gap is $0.015 \mathrm{~m}$. The thickness of the shield tail gap is $0.085 \mathrm{~m}$. In the numerical simulation, in order to simplify the calculation, the excavation gap is considered as an annular closed circle which is distributed in the radial direction between the shield shell and the surrounding soil, as shown in Figure 6.

In the calculation, it is assumed that the soil layers in each layer are homogeneous. The process of tunnel construction is modeled step by step. Each excavation step corresponds to a $1.5 \mathrm{~m}$ advance in the tunnel face. The Drucker-Prager constitutive model is used, and the C3D8P element is used. The fluid-solid coupling characteristics of the soil are considered in the analysis. The main physical and mechanical parameters of each soil layer are shown in Table 1 . All of the material parameters are obtained from the laboratory tests and the actual working conditions. The shield machine and the grouting were simulated by means of volume elements with perfect elastic behavior, assuming that the shield shell is approximately rigid and does not deform. The lining uses C50 concrete. Each ring segment is regarded as a whole ring in the simulation in this paper, which is different from the segment arrangement in practice. 


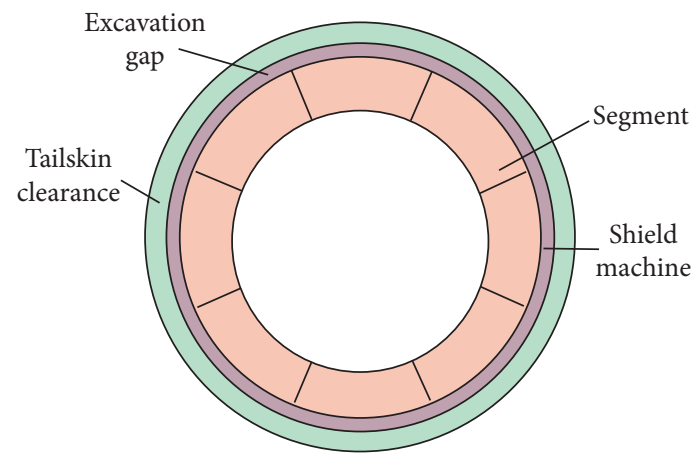

Figure 6: Numerical calculation of shield clearance.

TABLe 1: Mechanical properties of EPB components.

\begin{tabular}{lccc}
\hline Material properties & Bulk weight $\left(\mathrm{kg} / \mathrm{m}^{3}\right)$ & Elastic modulus $(\mathrm{MPa})$ & Initial void ratio \\
\hline Segment & 2500 & 29,300 & 0.16 \\
Shield & 7800 & 210,000 & 0.28 \\
Grout in soft phase & 2000 & 40 & 0.2 \\
Grout in hard phase & 2000 & 200 & 0.2 \\
Filling material & 2600 & Changing & 0.3 \\
\hline
\end{tabular}

Considering the weakening stiffness of the lining joint, the weakening factor is between 0.70 and 0.90 , and the material stiffness of the lining for circumferential direction was set as $85 \%$.

\subsection{Analysis of Backfilling Effect of Shield Clearance.} Shield excavation will produce excavation clearance and shield tail clearance. The thickness of shield tail clearance is usually 5-6 times that of excavation clearance. The influence of different filling amounts and filling materials on stratum displacement is also different. In numerical calculation, a linear elastic constitutive model is used to simulate filling materials, and a single variable is controlled. The elastic modulus of filling materials in excavation clearance and shield tail clearance is used to characterize the impact of these two factors. The influence of elastic modulus of filling materials in excavation clearance and shield tail clearance on surface displacement is analyzed. In a constant initial stress field, the settlement is approximately linearly related to the strain. The control mechanism of excavation clearance filling and shield tail clearance grouting on stratum displacement is analyzed, which provides a theoretical basis for the related research of similar strata.

The analysis shows that the elastic modulus of grouting material in excavation clearance and shield tail clearance can be exponentially related to the surface settlement value. Because the thickness of excavation clearance is small, the thickness of excavation clearance of this shield machine is only 0.176 times that of shield tail clearance. The filling material is quick-setting type, the loss is relatively small, the filling curve of excavation clearance converges faster, and the control effect of surface settlement in a certain range is more obvious than that of shield tail grouting. When the initial setting $E$ of shield tail gap grout is $40 \mathrm{MPa}$ and the final setting $E$ is $200 \mathrm{MPa}$, the relationship between the elastic modulus of filling material and the surface settlement is calculated. As shown in Figure 7, in the numerical calculation, when the elastic modulus of filling material in excavation clearance is $50 \mathrm{kPa}$, it is assumed that the excavation clearance is not filled, and the surface settlement value is $-51.28 \mathrm{~mm}$; when the elastic modulus of filling material is $1 \mathrm{MPa}$, it is simulated as a slight filling state, and then the surface settlement value is $-12.05 \mathrm{~mm}(1.86 \mathrm{D})$; when the elastic modulus of filling material is $10 \mathrm{MPa}$, the surface settlement reaches $-7.69 \mathrm{~mm}(1.19 \mathrm{D})$, and as a critical value, the surface subsidence has remained stable since then. In this stratum, the ground subsidence can be stabilized at $8 \mathrm{~mm}$ by filling the excavation clearance under certain grout conditions in the shield tail clearance.

When the elastic modulus of filling material is controlled at $10 \mathrm{MPa}$, the elastic modulus of initial setting and final setting of backfill slurry in shield tail gap is changed, the linear correlation between them is unchanged, and the elastic modulus increases equivalently, as shown in Figure 8. The control mechanism of elastic modulus of grout in shield tail clearance on surface subsidence is studied. There are three obvious inflection points in the curve. When the final setting modulus is less than $100 \mathrm{MPa}$, it has the most obvious effect on surface displacement, and the surface displacement decreases sharply. When the elastic modulus reaches $1000 \mathrm{MPa}$, the surface subsidence rate slows down, the grout stiffness increases, and the subsidence caused by formation loss is almost zero.

Due to the filling effect of excavation clearance, when the elastic modulus of the grout in the shield tail clearance is very small, the surface settlement is only 0.27 times that in the condition of no filling of excavation clearance. Therefore, the filling of excavation clearance can effectively reduce the formation loss within a certain range and play an auxiliary role in 


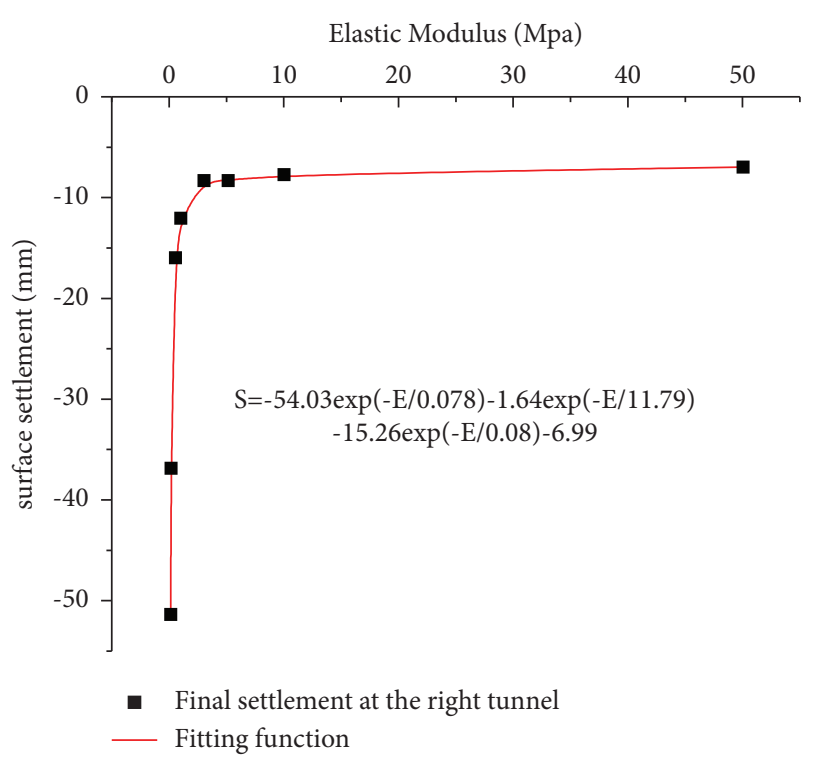

FIGURE 7: Excavation clearance fitting curve for the settlement obtained by numerical simulation.

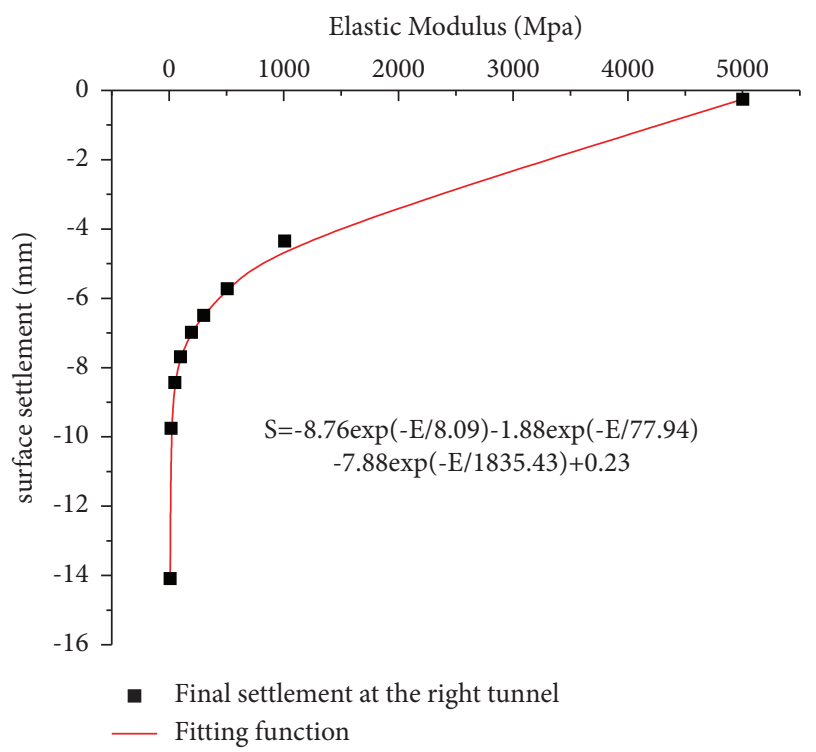

FIGURE 8: Shield tail clearance fitting curve for the settlement obtained by numerical simulation.

controlling the settlement of shield tail clearance grouting. However, as the elastic modulus of the filling of excavation clearance exceeds $50 \mathrm{MPa}$, it will no longer have a significant controlling effect on the surface displacement. According to the relevant specifications, there are different ground settlement control values in the face of risk sources and different stratum conditions around the tunnel. When faced with major risk sources, if settlement control is required to be less than $8 \mathrm{~mm}$ in the code, the elastic modulus of grout in the shield tail gap should be increased besides assistant control of excavation gap filling. The ground settlement of shield tunneling can be effectively controlled within a reasonable range by the interaction of filling material in excavation clearance and grout in shield tail clearance.
3.3. Shield Excavation Simulation Process. Since the filling material has a quick-setting property, only the simultaneous grouting hardening process is considered, and the excavation gap unit elastic modulus is set to $10 \mathrm{kPa}$ to simulate the excavation gap unfilled condition. The long-term strength of single-liquid grout used for back-wall grouting is $1 \sim 2 \mathrm{MPa}$, and the elastic modulus is $200 \mathrm{MPa}$. In the model, one unit is divided with an interval of $1.5 \mathrm{~m}$ along the direction of the shield machine, and one cycle lasts for $3 \mathrm{~h}$. The excavation gap is divided into two states: filling and nonfilling, as shown in Figures 9 and 10.

The excavation procedures of the tunnel in FE analysis are described as follows:

(1) Step 1: initialization is conducted.

(2) Step 2: in the finite element analysis, some units, such as the tube piece, the shield shell, and the grouting, are shielded to balance the ground stress.

(3) Step 3: the shield machine and the filling grout are activated, and corresponding soil elements are removed by the "element death" technique. The supporting pressure acts upon the tunnel face.

(4) Step 4: the advancement process of the shield machine is simulated by activating the new shield element in front of the shield shell and deactivating the front soil element. The applied supporting pressure in step 2 will be removed and activated on the new shield face. At the same time, the segment element and the softened grouting layer are activated, and the grouting pressure of the rear ring of the shield shell is uniformly applied to the surrounding soil.

The physical and mechanical parameters of the soil are listed in Table 2. According to the horizontal stress of the ground in front of the tunnel working face, the working face pressure is estimated. In the actual construction process, in order to offset the displacement of shield passing and shield tail coming out, the excavation surface soil is in the state of passive Earth pressure. Generally, the support pressure is greater than the Earth pressure [26]; as a result, the Earth pressure in the excavation chamber is set at about $0.2 \mathrm{MPa}$.

\section{Comparative Analysis of Calculated Results and Measured Results}

According to the measured data, a series of measuring points on the surface are selected. The arrangement of the measuring points is shown in Figure 11. The M4 and M9 measuring points are located at the surface above the axis of the left and right tunnels, respectively.

4.1. Measured Value and Calculated Value Time-History Law. Since the measured part only fills the excavation gap in part of the right line tunnel, the measured value of the M9 measuring point over a period of time is compared with the calculated value in the numerical calculation of the excavation gap filling state. 


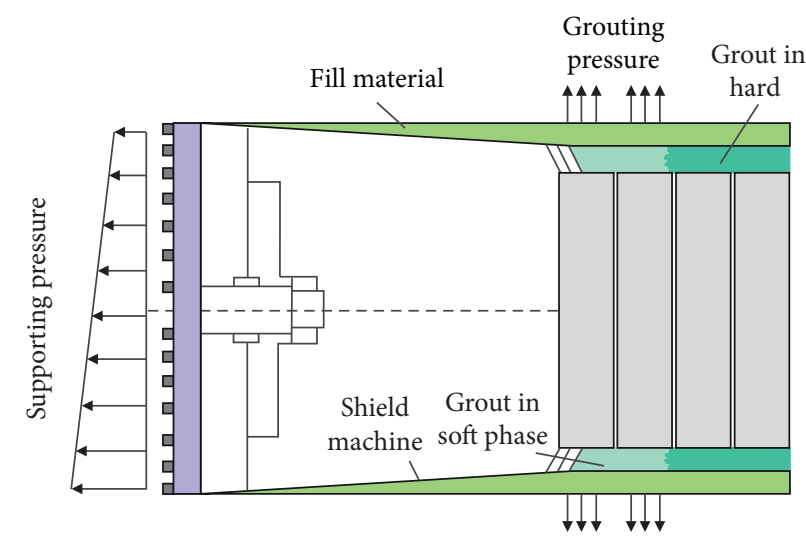

FIGURE 9: Simulated excavation gap is filling.

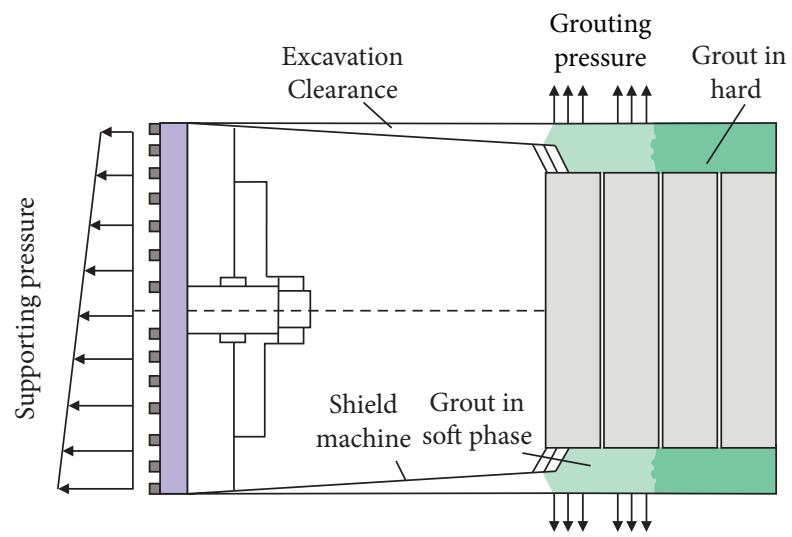

Figure 10: Simulated excavation gap is not filled.

TABle 2: Physical and mechanical properties of the soil.

\begin{tabular}{lccccc}
\hline Properties & Bulk weight $\left(\mathrm{kg} / \mathrm{m}^{3}\right)$ & Cohesion $(\mathrm{kPa})$ & Friction angle $\left(^{\circ}\right)$ & Elastic modulus $(\mathrm{MPa})$ & Initial void ratio \\
\hline Plain fill & 1750 & 8 & 10 & - & 5 \\
Sandy clay fill & 1980 & 16 & 32 & 26 & 9.3 \\
Sandy clay & 1920 & 0 & 12.7 & 4.2 & 0.23 \\
Organic silty clay & 1690 & 23 & 29 & 63 & 0.25 \\
Fine sand & 2070 & 0 & 0.31 \\
\hline
\end{tabular}
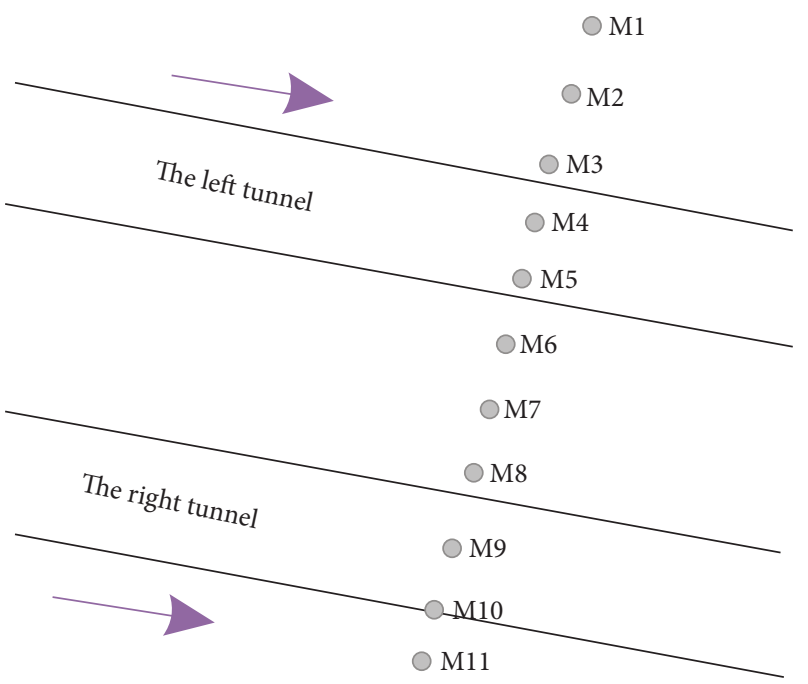

Figure 11: Layout of measurement points in tunnels. 
It can be seen from Figure 12 that, due to the role of supporting pressure, the surface measuring point is raised by about $3 \mathrm{~mm}$ under the filling condition. In the numerical calculation, the gap between the shield and the tail is simulated as completely filled. In actual construction, there may be a situation that the filling material is lost into the surrounding soil. Therefore, the measured value obtained at the stage after the shield tail is released can be obtained from the comparison analysis. Under the filling condition, the final settlement value is $7.99 \mathrm{~mm}$, the measured data is $7.89 \mathrm{~mm}$, and the error is small. In addition, it can be seen that the development trend of the calculated settlement curve is basically consistent with that of the measured data. These conclusions are in good agreement with field observations, which indicates that the numerical simulation can effectively simulate the working condition of filling in the excavation gap during the construction process. It can also reflect the change of surface displacement caused by tunnel construction.

4.2. Deformation of Ground Surface. After the tunnel excavation is completed, the numerical simulation results and measured data corresponding to the displacement measurement points at the surface and the fitting curve of Peck formula are compared, as shown in Figure 13. The two tunnels are not excavated synchronously due to the mutual influence between the two tunnels, so the settlement troughs that develop during tunneling are always asymmetrical. In the actual construction, only the right tunnel excavation gap is filled. So, the measured value is in the shape of "left big small right."

According to the Peck formula, under the assumption that the soil is undrained and the volume of the soil is equal to the volume of the "settlement trough" curve, it is considered that the settlement of the soil is caused by the loss of the formation, and the "settlement trough" curve has a normal distribution curve when the single tunnel is excavated. When the two tunnels are excavated, the settlement curves of the left and right tunnels are superimposed to obtain the total surface "settlement trough" curve. From the empirical method of Peck, it is known that the ground settlement $S(x)$ from the central axis of the tunnel is proportional to the maximum value of the surface settlement.

$$
S(x)=S_{\max } \cdot \exp \left(\frac{-x^{2}}{2 i^{2}}\right)
$$

where $S(x)$ is the transverse settlement at distance $x$ from the tunnel's centerline, $S_{\max }$ is the maximum settlement value of the ground surface at $x=0$, which is near the symmetry plane of the tunnel; $x$ is the horizontal distance of the symmetry plane of the tunnel. $i$ describes the location of the maximum settlement gradient.

$$
i=k z_{0},
$$

where $k$ is the "settlement trough" curve width parameter, which depends on the parameters of the soil.

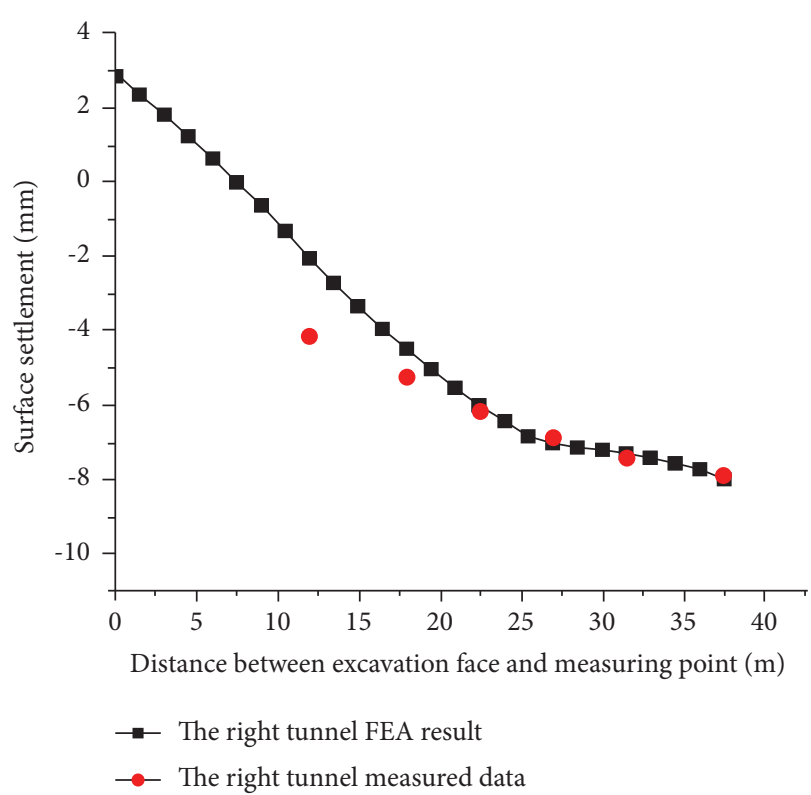

Figure 12: Comparative analysis of calculated value and monitoring value (excavation gap filling).

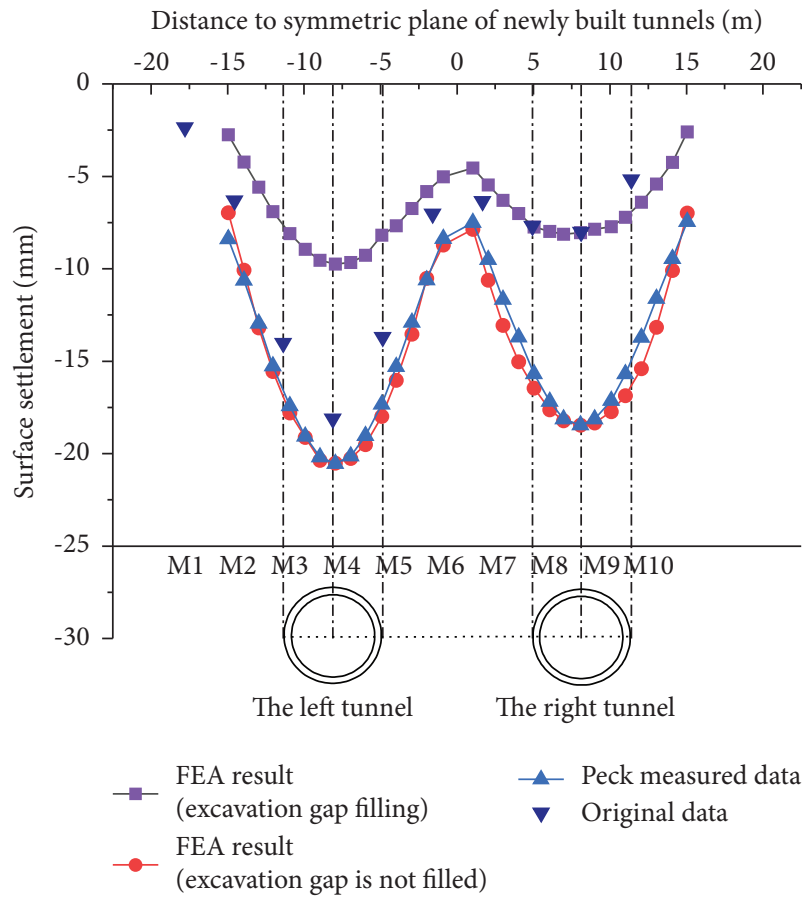

Figure 13: Comparison of ground surface settlement and the simulation results.

According to the corresponding parameters of the soil, the inverse algorithm is used to predict the deformation of the surface. The prediction curve agrees well with the surface deformation curve under the nonfilling condition in the numerical simulation. Therefore, it can be considered that the traditional Peck formula does not consider the influence of the excavation gap. At the same time, it can also be shown that the numerical simulation method can reasonably and effectively simulate the excavation gap without filling. 
Since the stress release of the soil in the simulation is earlier and faster than that in the actual construction and the replenishment grouting may influence the settlement in the actual construction, the calculated value at the end of the tunnel excavation is larger than the measured value. The maximum settlement value of the left tunnel in the simulation is $20 \mathrm{~mm}$. The maximum settlement value of the right tunnel is $18 \mathrm{~mm}$, and the error is $10 \%$. The maximum settlement value of the right tunnel in the simulation is $7.99 \mathrm{~mm}$. The maximum settlement value of the right tunnel is $7.91 \mathrm{~mm}$, with a $1 \%$ error. The measured curve of the left tunnel corresponds to the "settlement trough" curve of the left unfilled tunnel, and the measured curve of the right tunnel corresponds to the curve filled in the numerical simulation. The simulated calculated value agrees well with the measured value, thus verifying the correctness of the research method. The numerical analysis could provide some reference value for actual construction.

\section{FEA Results and Analysis}

The surface measurement points and formation measurement points are, respectively, arranged in the numerical observation section $(y=37.5 \mathrm{~m})$. The influence of boundary conditions on tunnel behavior is negligible in this section, as shown in Figures 14 and 15. The measuring points at the surface are, respectively, used for observing the lateral influence range of the surface. Measuring points with a depth of $3.9 \mathrm{~m}(0.6 \mathrm{D})$ and $8.5 \mathrm{~m}(1.3 \mathrm{D})$ are, respectively, located in the stratum $1 \mathrm{~m}$ directly above the sewage pipe and the stratum $0.9 \mathrm{~m}$ directly above the newly built tunnel. B1 B31 and $\mathrm{C} 1 \sim \mathrm{C} 31$ are used to observe the horizontal influence range in the deep stratum. Fourteen measuring points are arranged at different depths of the stratum, namely, S1 S14, for observing the distribution law of lateral and longitudinal displacement fields of deep soil during the process of shield tunneling.

5.1. Impact Range of Tunnel Excavation. The influences of the excavation gap filling on the vertical displacement of the stratum and the development trend of the settlement trough are analyzed by selecting the lateral observation points at $3.9 \mathrm{~m}$ and $8.5 \mathrm{~m}$.

Figures 16 and 17 show the development of surface "settlement trough" curves during the tunneling of the new tunnel at different depth. At the same time, a comparison of the final settlement troughs for different construction procedures (excavation gap filling and excavation gap nonfilling) is performed. Figures 16 and 17 show the shape of the "settlement trough" curve above the left tunnel changes from "wide and shallow" to "narrow and deep." The settlement trough caused by the excavation of the right tunnel is shallower and wider than the left tunnel. As the tunnel excavation is completed, the curve of the two states of the excavation gap shows an obvious settlement difference, and the vertical displacement increases sharply with the increase of the strata depth. When the left tunnel is excavated, the settlement of the measurement points at a depth of $3.9 \mathrm{~m}$ is

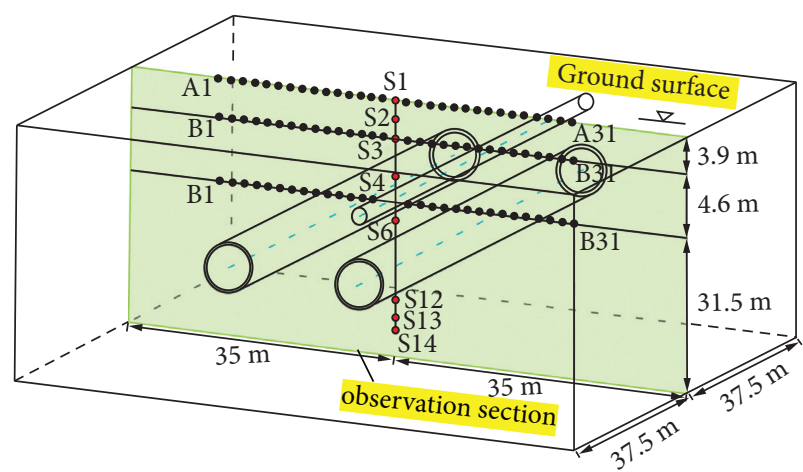

FIgURE 14: Observation section in numerical simulation.

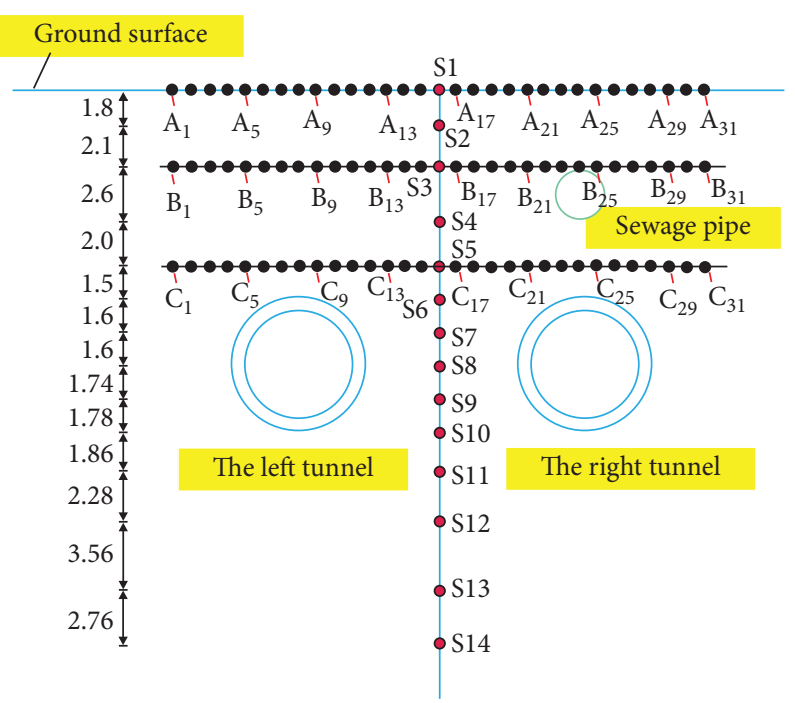

FIGURE 15: Layout of observation points in numerical simulation.

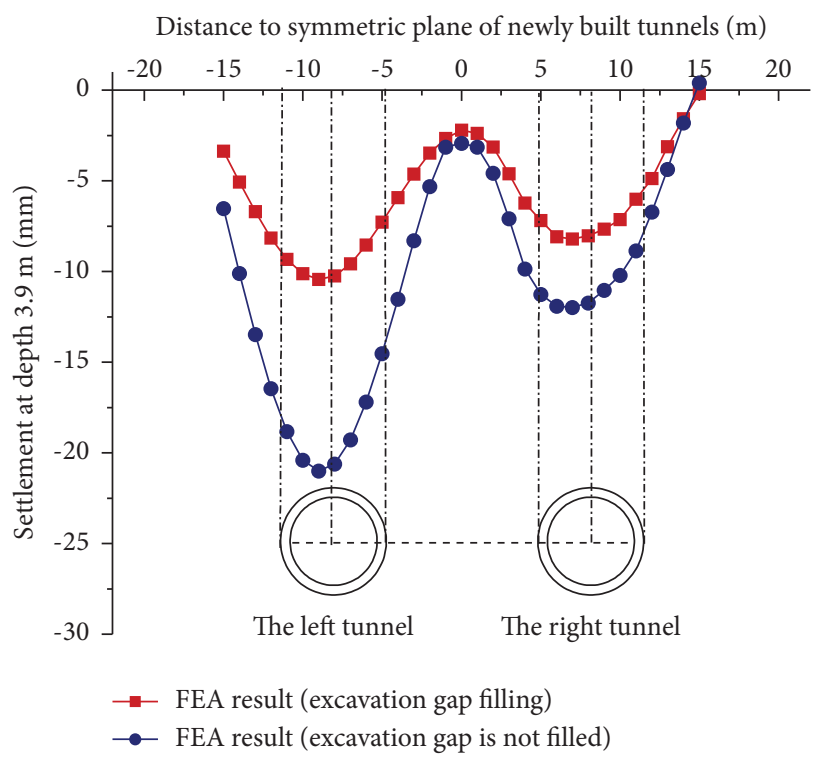

FIgURE 16: $3.9 \mathrm{~m}$ depth simulation results. 


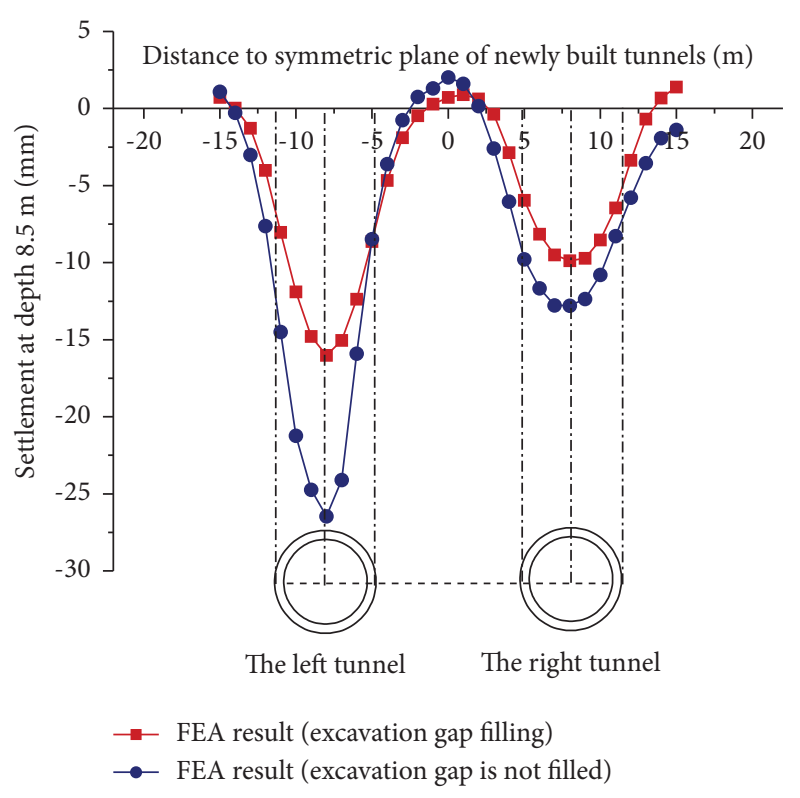

Figure 17: $8.5 \mathrm{~m}$ depth simulation results.

reduced by about $10.69 \mathrm{~mm}(0.165 \% \mathrm{D})$ after filling the excavation gap. At a depth of $8.5 \mathrm{~m}$, the maximum vertical displacement difference between the filling and nonfilling conditions of the left line tunnel is $10.57 \mathrm{~mm}(0.163 \% \mathrm{D})$. The right tunnel is still at the late stage of settlement, so the settlement difference is small. The comparative analysis shows that the excavation gap filling can effectively control the displacement of the soil around the shield and the sewage pipe.

5.2. Horizontal Impact Range of Deep Strata. The different depth measuring points S1 S14 at the two tunnel axes of the observation section are selected to analyze the influence of the filling gap on the horizontal and longitudinal displacement of the measuring point during the excavation process of the left tunnel and the right tunnel. The positive and negative displacement correspond to the displacement to the right tunnel and the displacement to the left tunnel. When the horizontal displacement is positive, the measuring point is toward the right tunnel.

The variations of the horizontal displacement along the center axis of two tunnels during the advancement of a single tunnel on the left are shown in Figures 18 and 19.

The development trend of horizontal displacement of the stratum is mainly divided into the following three stages:

(1) When the shield is far away from the observation section, the soil stress is released due to the disturbance of the head cutter on the soil. The soil between the top of the tunnel and the invert moves outward due to the supporting force of the working face.

(2) When the cutterhead arrives at the observation section, due to the insufficient self-stabilization ability of the gap between the shield shell and surrounding rock, the soil moves toward the tunnel. Under the unfilled condition, the trend of moving is becoming

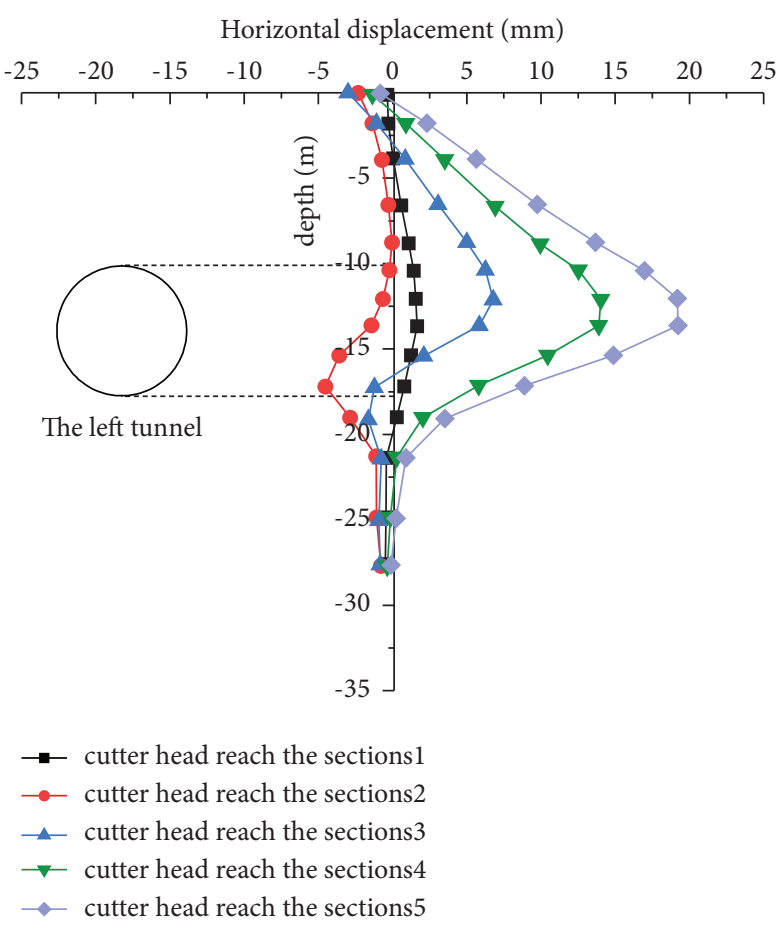

Figure 18: The left tunnel excavation gap is not filled.

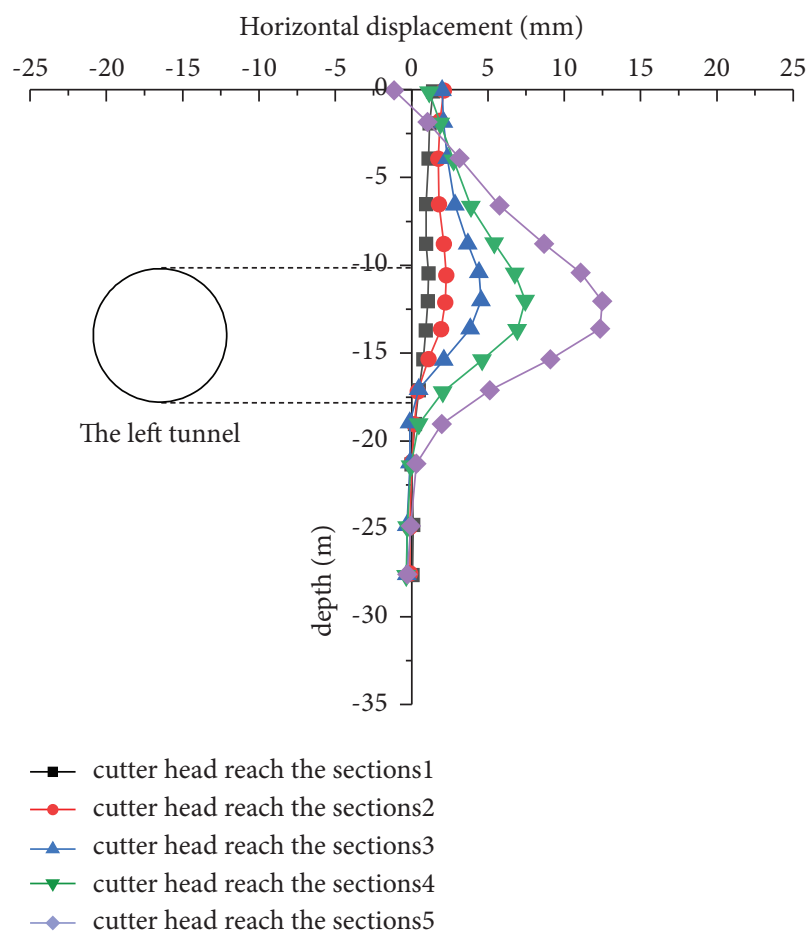

FIgURE 19: The left tunnel excavation gap filling.

more apparent with a smaller distance between the cutterhead and the observation section. Under the filling condition, the measuring point moves slightly to the right at this stage due to the squeezing effect.

(3) When the cutterhead is $7.5 \mathrm{~m}$ ahead of the monitoring section (as shown in Figure 14), the soil at the tail 
of the shield moves outward again due to the grouting pressure. These outward motions continue until a stable state due to grouting hardening and low value of the soil pressure. The final offset value of the measuring point is $19.57 \mathrm{~mm}(0.3 \% \mathrm{D})$ under the unfilled condition, and the final offset value of the measuring point under the filling condition is $12.62 \mathrm{~mm}(0.195 \% \mathrm{D})$.

As shown in Figures 20 and 21, soil mass moves to the left of the tunnel due to the action of grouting pressure. The movement value of the right tunnel decreases as the distance between the cutterhead and the monitoring section decreases. The horizontal displacement reaches the peak before the right line shield cutterhead reaches the monitoring section. The shape and development trend of the deep displacement field are basically similar under the two conditions, and the maximum offset value has obvious deviation. When the tunnel is excavated, the maximum offset of the measuring points under the two working conditions differs by about $6.68 \mathrm{~mm}(0.1 \% \mathrm{D})$. Under the condition of excavation gap filling, the soil mass zone below the tunnel is more stable. The right tunnel excavation grouting has a "compensation" effect on the horizontal displacement caused by the left tunnel excavation; that is, the horizontal displacement that has been formed is reduced.

Under the filling or unfilled condition, the lateral displacement of the deep stratum is shown in Table 3 .

5.3. Longitudinal Impact Range of Deep Strata. The settlement of shield tunnel excavation is mainly divided into five stages (as shown in Figure 22): the advance impact stage, the shield arrival stage, the shield passage stage, the shield tail release stage, and the long-term settlement stage.

We divide evidence of the five stages:

Stage I: $(-6$ to -2$)$ D. Due to different formation conditions, the initial position is different. At this stage, the average settlement rate is very small, and the strata will be uplifted under the action of shield supporting pressure.

Stage II: $(-2.5 \sim 0)$ D. According to the statistical results and soil movement, angles $\left(45^{\circ} \pm(\theta / 2)\right)$ were divided. Due to the disturbance of the cutter disc to the soil ahead, the stratum uplift starts to decrease until subsidence occurs.

Stage III: $1 \mathrm{D}$. At this stage, the average settlement rate reaches the maximum, and the settlement is mainly caused by the excavation clearance.

Stage IV: (1 2) D. The average settlement velocity at this stage is still very high, and the settlement is caused by the gap of the shield tail.

Stage V: (2 6) D. The average settlement velocity decreases until it is stable, which is caused by soil creep or compression consolidation settlement.

The excavation gap filling is mainly used to effectively control the third stage settlement caused by the shield advance and assist the control of the remaining four stages of settlement.

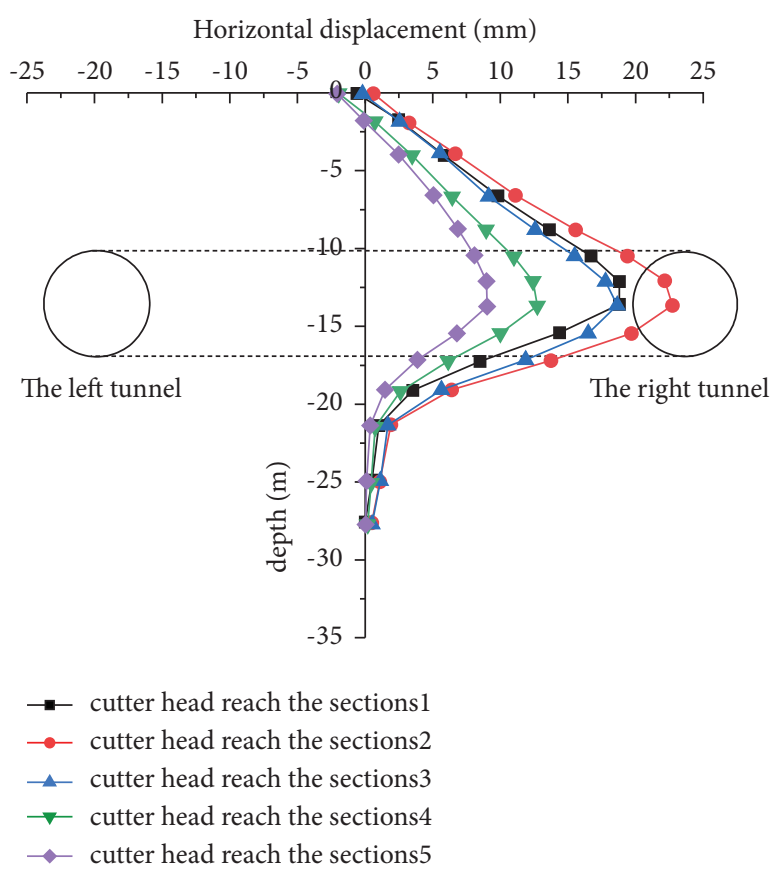

Figure 20: The right tunnel excavation gap is not filled.

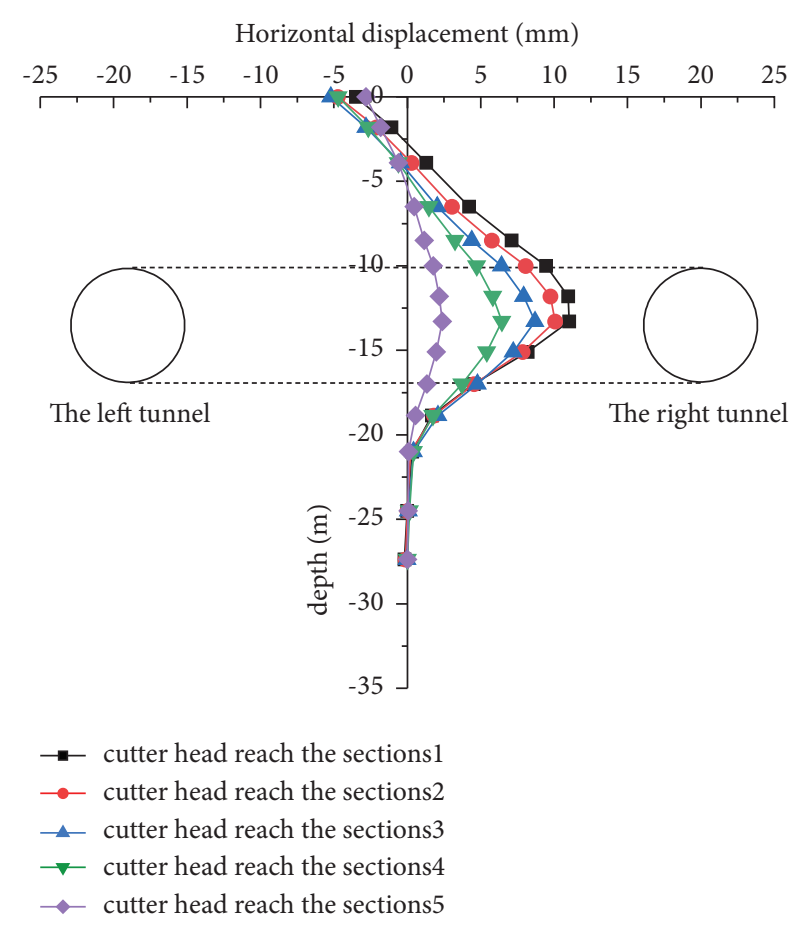

Figure 21: The right tunnel excavation gap filling.

The influence of the excavation gap filling on the longitudinal displacement of the left tunnel and the right tunnel is studied by analyzing the observation points S1 S14. A positive longitudinal displacement is a movement away from the support surface, and a negative value is the opposite.

The effect of left tunnel excavation on the longitudinal displacement is shown in Figures 23 and 24. When the excavation gap is filled and supported by the supporting 
TABLE 3: Lateral displacement of the deep stratum.

\begin{tabular}{|c|c|c|c|c|c|c|}
\hline & & $\begin{array}{l}\text { The left } \\
\text { tunnel }\end{array}$ & $\begin{array}{l}\text { The right } \\
\text { tunnel }\end{array}$ & & $\begin{array}{l}\text { The left } \\
\text { tunnel }\end{array}$ & The right tunnel \\
\hline \multirow{2}{*}{$\begin{array}{l}\text { Excavation gap is not } \\
\text { filled }\end{array}$} & $\begin{array}{l}\text { Max. pos. displacement } \\
(\mathrm{mm})\end{array}$ & 19.26 & 22.7 & $\begin{array}{l}\text { Max. neg. displacement } \\
(\mathrm{mm})\end{array}$ & -4.52 & -2.1 \\
\hline & Depth $(\mathrm{m})$ & -13.65 & -13.65 & Depth $(\mathrm{m})$ & -17.17 & 0 \\
\hline \multirow{2}{*}{ Excavation gap filling } & $\begin{array}{l}\text { Max. pos. displacement } \\
(\mathrm{mm})\end{array}$ & 12.31 & 10.09 & $\begin{array}{l}\text { Max. neg. displacement } \\
(\mathrm{mm})\end{array}$ & -1.15 & -5.17 \\
\hline & Depth $(\mathrm{m})$ & -13.65 & -13.65 & Depth $(\mathrm{m})$ & 0 & 0 \\
\hline
\end{tabular}

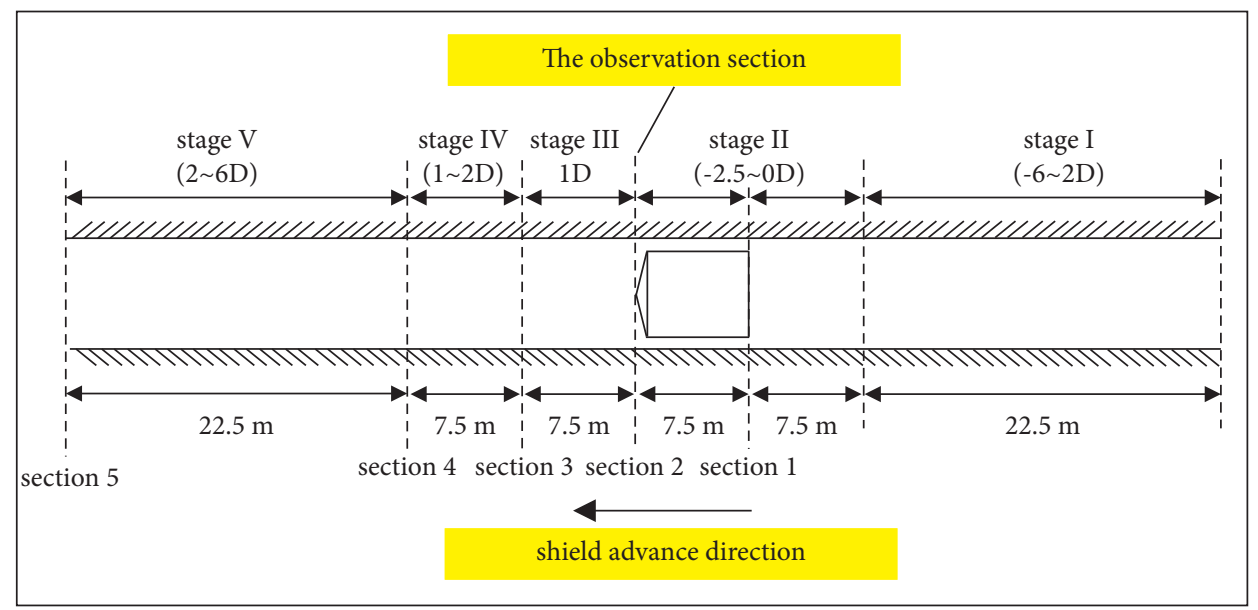

FIGURE 22: Simulation diagram of shield advance process.

pressure, the longitudinal displacement of the measuring point is relatively larger. When the excavation gap is not filled, the longitudinal displacement of the measuring point decreases when the cutterhead reaches the section. Affected by the cutter disc disturbance, soil mass moves to the excavation gap, and the support surface stability has an adverse effect. The frictional action of the shield machine moves forward, the surrounding soil causes shear deformation of the upper soil, and the longitudinal displacement of the shield tail is maximized.

The overlapping effect of the left tunnel and the right tunnel excavation is known shown in Figures 25 and 26. Under the filling condition, the longitudinal displacement at the central axis of the right tunnel is $2.74 \mathrm{~mm}$ larger than that at the left tunnel, and the maximum longitudinal displacement of the right tunnel is $7.89 \mathrm{~mm}$.

When the excavation gap is not filled, the cutterhead reaches the section, the soft soil layer below the tunnel moves to the cutter disc and the trajectory is deformed. At the same time, due to the existence of the supporting force, the displacement curve shows a " $Z$ " shape. When the shield passes the stage, the measuring point at the position of the right tunnel axis is shifted to the cutterhead by $1.45 \mathrm{~mm}$, and the longitudinal displacement of the left tunnel to the formation is more obvious.

Under the filling and unfilled conditions, the longitudinal displacement of the deep stratum is shown in Table 4 .

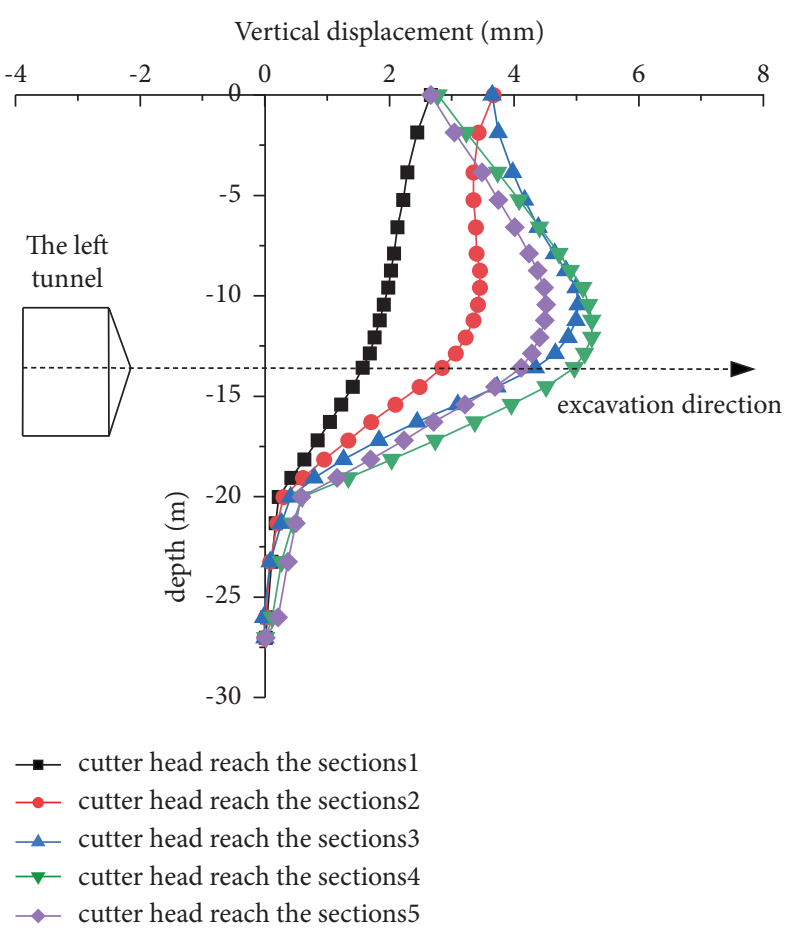

Figure 23: The left tunnel excavation gap filling. 


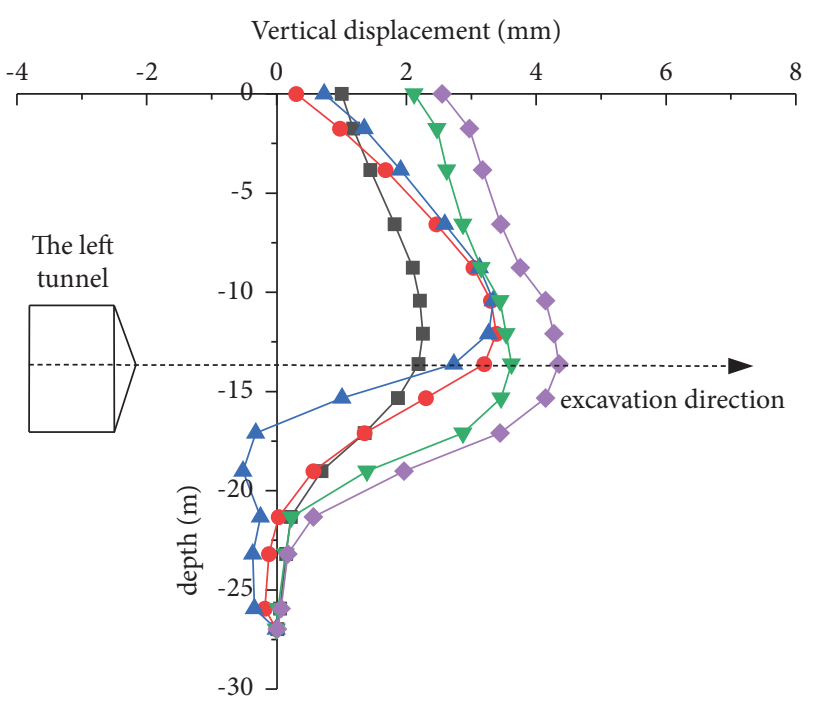

- cutter head reach the sections1

$\rightarrow$ cutter head reach the sections 2

$\rightarrow$ cutter head reach the sections 3

$\checkmark-$ cutter head reach the sections 4

$\checkmark$ cutter head reach the sections5

FIgure 24: The left tunnel excavation gap is not filled.

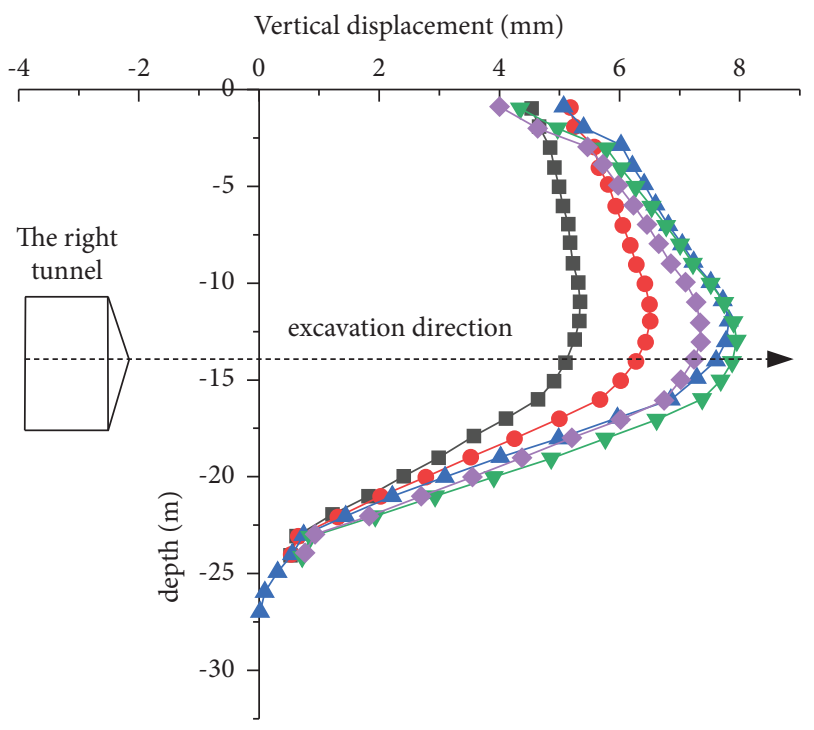

$\rightarrow$ - cutter head reach the sections 1

$\rightarrow$ cutter head reach the sections2

- - cutter head reach the sections 3

$\checkmark$ cutter head reach the sections 4

$\neg-$ cutter head reach the sections5

FIgURe 25: The right tunnel excavation gap filling.

5.4. Deformation Characteristics of Sewage Pipes. During the process of tunnel excavation, the underground pipeline will have an inevitable impact, especially in the soft soil area [27]. The load caused by the excavation of the new tunnel is transmitted through the stratum movement, which affects the existing underground pipeline. However, in order to highlight

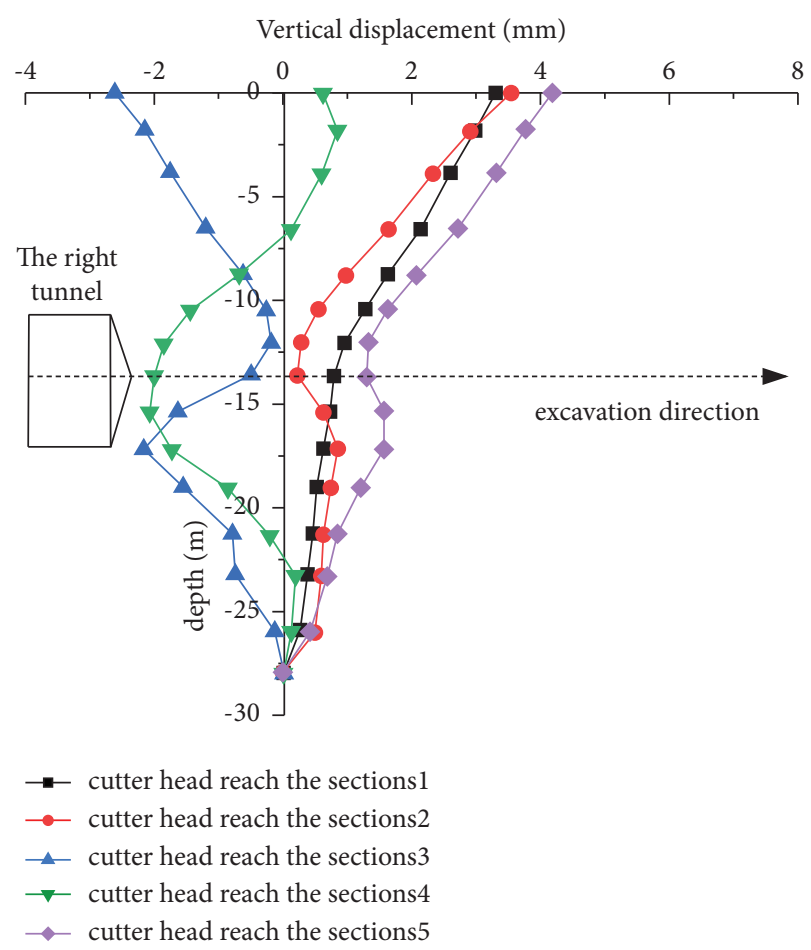

FIgURE 26: The right tunnel excavation gap is not filled.

the influence of the excavation process of a new tunnel on an existing sewage pipe, the top of the sewage pipe at the observation section (point A), bottom (point C), left side (point $\mathrm{B}$ ), and right side (point $\mathrm{D}$ ) are selected as monitoring points. The layout of the measuring points is shown in Figure 27. The direction judgment principle of the displacement value is the same as the formation measurement point.

The displacement of the sewage pipe is mainly caused by the excavation of the left tunnel. The vertical displacement of the sewage pipe measuring point is shown in Table 5. The sewage pipe has about $10 \%$ vertical extrusion deformation under the condition that the excavation gap is not filled. When the excavation gap is filled, the soil is restrained from moving toward the excavation gap, the stratum is relatively more stable, and the sewage pipe has about $7 \%$ vertical extrusion deformation. It can be obtained that the excavation gap filling can not only inhibit the rotation and extrusion deformation of the sewage pipe but also reduce the final settlement of the sewage pipe (as shown in Figure 28) and control the final settlement of each measuring point of the sewage pipe within $9 \mathrm{~mm}$. As a result, uneven settlement of sewage pipe joint fracture can be avoided.

It can be seen from Table 6 that the sewage pipe is displaced away from the tunnel due to the squeezing action of the cutterhead and the influence of the simultaneous backfilling injection pressure during the tunneling of the left tunnel. The excavation gap filling can reduce the lateral displacement by about 1.64 times at point $\mathrm{B}$, and the horizontal displacement of the sewage pipe is more obvious than the vertical displacement. The squeezing effect of the cutterhead and the influence of the grouting pressure cause the sewage pipe to shift away from the tunnel. 
TABLE 4: Longitudinal displacement of the deep stratum. \begin{tabular}{l}
$\begin{array}{l}\text { Excavation gap is not filled } \\
(\mathrm{mm})\end{array}$ \\
\hline
\end{tabular}

\begin{tabular}{lccccc}
\hline Max. pos. displacement & 4.33 & 4.16 & Max. pos. displacement & 5.26 & 7.34 \\
Depth & 13.65 & 0 & Depth & 11.25 & 12 \\
\hline
\end{tabular}

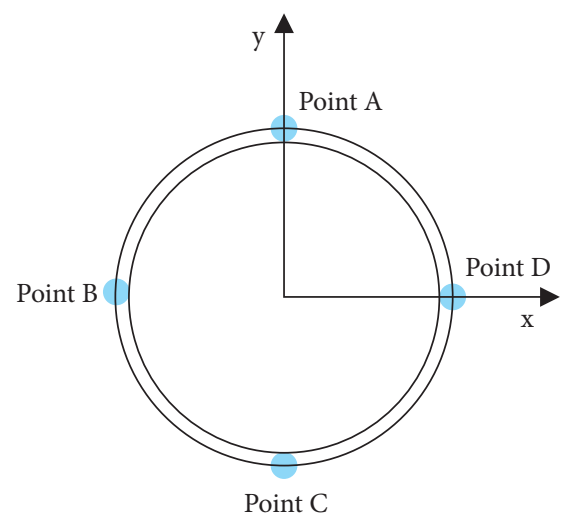

FIGURE 27: Layout of observation points in numerical simulation.

TABLE 5: Sewage pipe measuring point vertical displacement.

\begin{tabular}{lcccc}
\hline Vertical displacement $(\mathrm{mm})$ & Excavation gap (filling) & $\begin{array}{c}\text { Excavation gap (is } \\
\text { not filled) }\end{array}$ & Error & Percentage of error \\
\hline A & -8.06 & -11.98 & 3.92 & 32.7 \\
B & -7.24 & -11.90 & 3.92 & 39.15 \\
C & -6.31 & -10.89 & 4.58 & 42 \\
D & -7.15 & -10.89 & 4.04 & 36.1 \\
\hline
\end{tabular}

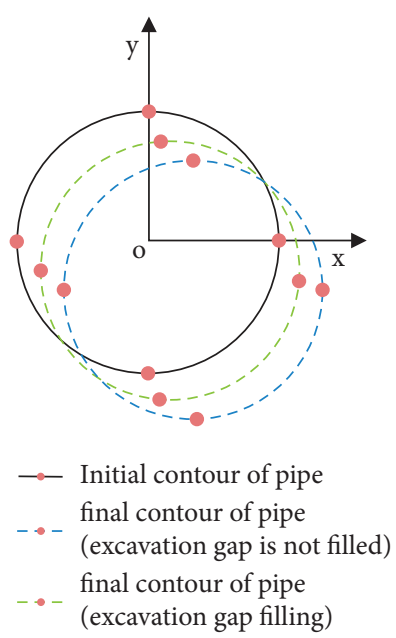

Figure 28: Sewage pipe displacement.

TABLE 6: Sewage pipe measuring point horizontal displacement.

\begin{tabular}{lcccc}
\hline Horizontal displacement $(\mathrm{mm})$ & Excavation gap (filling) & Excavation gap (is not filled) & Error & Percentage of error \\
\hline A & 4.41 & 10.40 & 5.99 & 57.6 \\
B & 4.59 & 10.72 & 6.13 & 57.2 \\
C & 4.71 & 10.96 & 6.25 & 57 \\
D & 4.53 & 10.63 & 6.1 & 57.38 \\
\hline
\end{tabular}




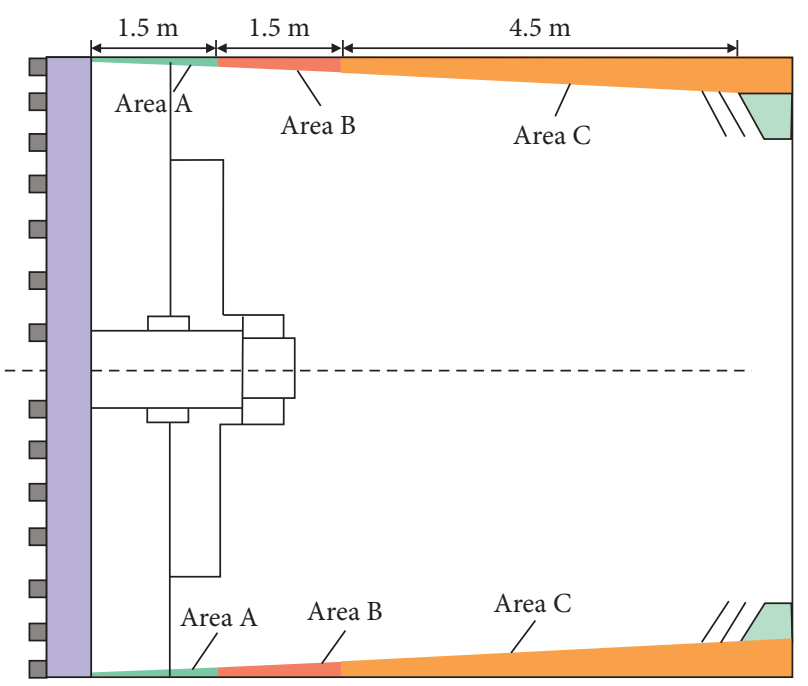

FIgURE 29: Shield excavation gap filling area.

\section{Influence of the Excavation Gap Filling Area on Stratum Displacement}

The excavation gap filling material has a rapid setting, so the filling area is predictable. Filling in the front shield may cause the loss of filling material into the cutterhead, which may increase the cutter torque. Filling the shield tail will not effectively control the stability of the soil layer above the excavation gap. Therefore, the filling performance can be modified by reasonable and effective filling. The effect has become a difficult problem at present. Therefore, the model observation section is used to measure the stratum, and the shield shell area is divided into three parts: A, B, and C. As shown in Figure 29, the proportion of settlement at different stages is calculated. The influence of filling at different areas on the settlement ratio and the settlement rate at each stage is studied.

6.1. Influence of the Excavation Gap Filling Area on the Proportion of Settlement in Each Stage. The influence of grouting in the excavation gap on the settlement value of each stage is studied. The proportion of the settlement point at each stage of the tunnel axis is described. The definition is as follows:

percentage of settlement at each stage $(\%)=\frac{\text { the settlement increment of the measuring point above the tunnel axis at each stage }(\mathrm{mm})}{\text { final settlement value of measuring point above the tunnel axis }(\mathrm{mm})} \times 100 \%$.

As shown in Figure 30, under the full filling condition, the measuring point is in a bulging state before the cutterhead arrives, the sedimentation percentage is 0 , and the settlement is mainly concentrated at the postrelease phase of the shield tail. At this time, the slurry has not hardened, the self-stability of the formation is insufficient, and the overall stiffness of the filling material and grout in the shield tail clearance is less than that in the nonfilling condition. It can be seen that the complete filling condition has the largest percentage of sedimentation after the shield tail is released.

Under the condition that the excavation gap is not filled, the settlement mainly occurs at the cutterhead approaching stage and the shield passing stage, and the formation displacement is reduced due to the synchronous grouting of the shield tail gap after the shield tail is released.

6.2. Influence of the Excavation Gap Filling Area on Average Settlement Rate of Each Stage. The influence of grouting in the excavation gap on the average settling velocity of each stage is studied. The settlement increment above the tunnel axis is used to explain the settlement increment per unit time in each stage. The definition is as follows:

$$
\text { average settlement rate at each stage }(\mathrm{mm} / \mathrm{d})=\frac{\text { settlement value in each stage }(\mathrm{mm})}{\text { shield through the various stages of time }(\mathrm{d})} \text {. }
$$




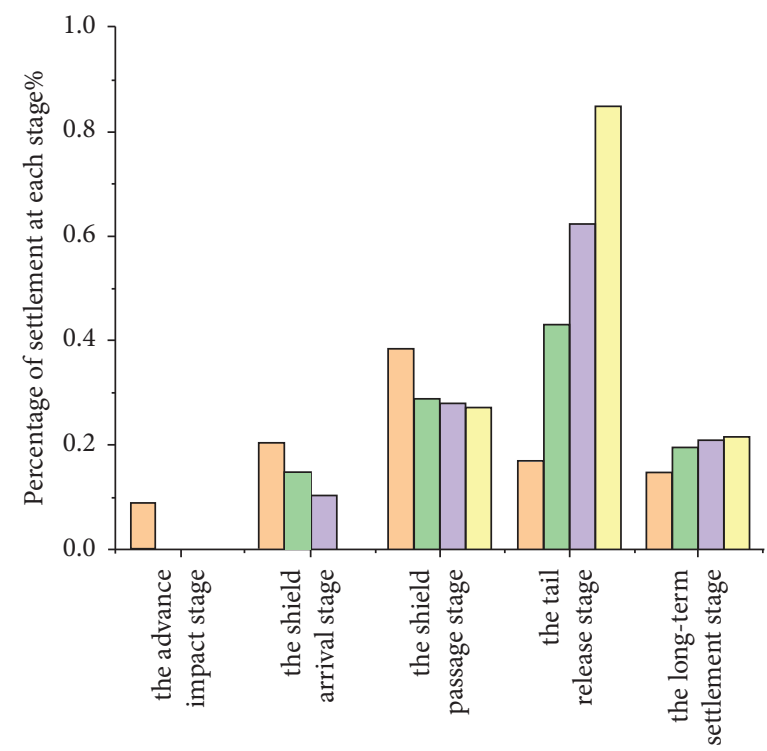

$\square$ Excavation gap is not filled

Excavation gap filling $\mathrm{C}$ area

Excavation gap filling $\mathrm{B}$ and $\mathrm{C}$ area

Excavation gap full filling

Figure 30: Proportion of settlement at each stage.

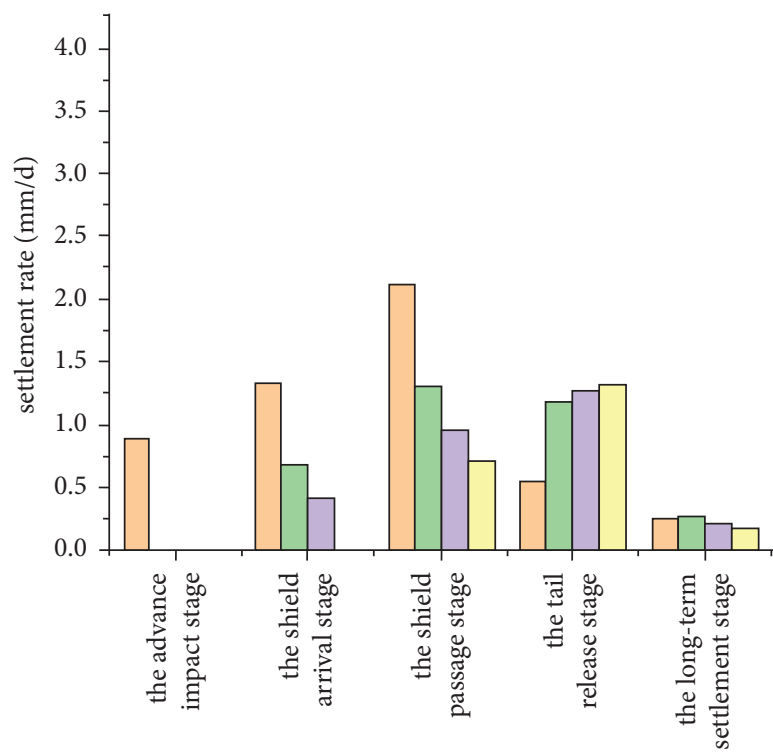

Excavation gap is not filled

Excavation gap filling $\mathrm{C}$ area

Excavation gap filling $\mathrm{B}$ and $\mathrm{C}$ area

Excavation gap full filling

FIgURE 31: Settling rate at each stage.

It can be concluded from Figure 31 that when the excavation gap is not filled, the settlement rate of the measuring point reaches a maximum value of $2.12 \mathrm{~mm} / \mathrm{d}$ at the passage stage of the shield. With a smaller filling area in the excavation gap at this stage, the rate of settling is greater. At the postprogression phase, the opposite 
phase is due to the fact that the settlement of the measuring points is mainly concentrated at the fourth stage, and the measuring points at the first two stages are all in the uplifted state. Therefore, the filling of the excavation gap can inhibit the settlement at the second and third stages and has less influence on the later settlement.

\section{Conclusions}

(1) The excavation clearance filling can reduce the vertical displacement of the stratum and inhibit the movement of soil toward the excavation surface. In addition, the subsidence rate can be effectively reduced, and the settlement value stabilizes faster. The reduced vertical displacement of the stratum shows that the shape of the settlement trough changes from "narrow and deep" to "shallow and wide" after filling.

(2) Different projects have different requirements for stratum settlement control, and the filling materials used will also be different. Through the relationship curve between the elastic modulus of filling materials and the stratum displacement, the reference value of the minimum elastic modulus of filling materials in line with the safety standards of this project can be obtained, which can guide the selection of construction materials.

(3) The numerical results of the tunnel surface settlement are basically consistent with field measured data, indicating that finite element simulation can well reflect the influence of excavation clearance grouting on the surrounding soil. Filling the excavation gap with materials with short hardening time, high elastic modulus, and low shear strength can effectively control the settlement at the critical stage of shield tunneling and provide theoretical reference for the study of new material grouting and prediction of grouting area.

(4) The excavation gap filling material with clay shock material can reduce the extrusion deformation of sewage pipe and the deviation of sewage pipe measuring point by about $57 \%$. The rotational and lateral movement of sewage pipe can be inhibited to a certain extent, which reduces the risk of sewage pipe joint rupture.

\section{Data Availability}

The data used to support the findings of this study are available from the corresponding author upon request.

\section{Conflicts of Interest}

The authors declare that they have no conflicts of interest.

\section{Acknowledgments}

Financial support for this work provided by the Youth Program of the National Natural Science Foundation of China (Grant no. 51608521) is gratefully acknowledged.

\section{References}

[1] R. Chen, F. Meng, Z. Li, Y. Ye, and J. Ye, "Investigation of response of metro tunnels due to adjacent large excavation and protective measures in soft soils," Tunnelling and Underground Space Technology, vol. 58, pp. 224-235, 2016.

[2] X. T. Lin, R. P. Chen, H. N. Wu, and H. Z. Cheng, "Deformation behaviors of existing tunnels caused by shield tunneling undercrossing with oblique angle," Tunnelling and Underground Space Technology, vol. 89, pp. 78-90, 2019.

[3] X. G. Li and D. J. Yuan, "Response of a double-decked metro tunnel to shield driving of twin closely under-crossing tunnels," Tunnelling and Underground Space Technology, vol. 28, pp. 18-30, 2012.

[4] A. Sirivachiraporn and N. Phienwej, "Ground movements in EPB shield tunneling of Bangkok subway project and impacts on adjacent buildings," Tunnelling and Underground Space Technology, vol. 30, pp. 10-24, 2012.

[5] V. Avgerinos, D. M. Potts, and J. R. Standing, "Numerical investigation of the effects of tunnelling on existing tunnels," Géotechnique, vol. 67, no. 9, pp. 802-822, 2017.

[6] D. Jin, D. Yuan, X. Li, and H. Zheng, "An in-tunnel grouting protection method for excavating twin tunnels beneath an existing tunnel," Tunnelling and Underground Space Technology, vol. 71, pp. 27-35, 2018.

[7] N. A. Do, D. Dias, P. Oreste, and I. Djeran-Maigre, "Threedimensional numerical simulation of a mechanized twin tunnels in soft ground," Tunnelling and Underground Space Technology, vol. 42, pp. 40-51, 2014.

[8] Y. Tian, H. Liu, X. Jiang, and R. Yu, "Analysis of stress and deformation of a positive buried pipe using the improved Spangler model," Soils and Foundations, vol. 55, no. 3, pp. 485-492, 2015.

[9] Y. Wang, Q. Wang, and K. Y. Zhang, "An analytical model for pipe-soil-tunneling interaction," Procedia Engineering, vol. 14, pp. 3127-3135, 2011.

[10] Z. Zhang and M. Zhang, "Mechanical effects of tunneling on adjacent pipelines based on Galerkin solution and layered transfer matrix solution," Soils and Foundations, vol. 53, no. 4, pp. 557-568, 2013.

[11] J. I. Choi and S. W. Lee, "Influence of existing tunnel on mechanical behavior of new tunnel," KSCE Journal of Civil Engineering, vol. 14, no. 5, pp. 773-783, 2010.

[12] X. Li and X. Chen, "Using grouting of shield tunneling to reduce settlements of overlying tunnels: case study in Shenzhen metro construction," Journal of Construction Engineering and Management, vol. 138, no. 4, pp. 574-584, 2012.

[13] C.-S. Wu and Z.-D. Zhu, "Analytical method for evaluating the ground surface settlement caused by tail void grouting pressure in shield tunnel construction," Advances in Civil Engineering, vol. 2019, Article ID 3729143, 10 pages, 2018.

[14] C. L. Li, "Simplified algorithm for grouting pressure and grouting quantity in shield construction," International Journal of Civil Engineering, vol. 18, no. 4B, pp. 419-428, 2019.

[15] R. Shah, A. Lavasan, D. Peila, C. Todaro, A. Luciani, and T. Schanz, "Numerical study on backfilling the tail void using a two-component grout," Journal of Materials in Civil Engineering, vol. 30, no. 3, Article ID 4018003, 2018.

[16] J. Y. Oh and M. Ziegler, "Investigation on influence of tail void grouting on the surface settlements during shield tunneling using a stress-pore pressure coupled analysis," KSCE Journal of Civil Engineering, vol. 18, no. 3, pp. 801-811, 2014.

[17] T. Zhao, W. Ding, Y. Qiao, and C. Duan, "A large-scale synchronous grouting test for a quasi-rectangular shield 
tunnel: observation, analysis and interpretation," Tunnelling and Underground Space Technology, vol. 91, Article ID 103018, 2019.

[18] W. Ding, C. Duan, Y. Zhu, T. Zhao, D. Huang, and P. Li, "The behavior of synchronous grouting in a quasi-rectangular shield tunnel based on a large visualized model test," Tunnelling and Underground Space Technology, vol. 83, pp. 409-424, 2019.

[19] F. Ye, T. Yang, J. H. Mao, X. Z. Qin, and R. L. Zhao, "Halfspherical surface diffusion model of shield tunnel back-fill grouting based on infiltration effect," Tunnelling and Underground Space Technology, vol. 83, pp. 274-281, 2019.

[20] X. Xie, Y. Yang, and M. Ji, "Analysis of ground surface settlement induced by the construction of a large-diameter shield-driven tunnel in Shanghai, China," Tunnelling and Underground Space Technology, vol. 51, pp. 120-132, 2016.

[21] K. Michael, L. Dimitris, V. Ioannis, and F. Petros, "Development of a 3D finite element model for shield EPB Tunnelling," Tunnelling and Underground Space Technology, vol. 65, pp. 22-34, 2017.

[22] M. Sharghi, H. Chakeri, and Y. Ozcelik, "Investigation into the effects of two component grout properties on surface settlements," Tunnelling and Underground Space Technology, vol. 63, pp. 205-216, 2017.

[23] D. Jin, D. Yuan, X. Li, and H. Zheng, "Analysis of the settlement of an existing tunnel induced by shield tunneling underneath," Tunnelling and Underground Space Technology, vol. 81, pp. 209-220, 2018.

[24] M. Yin, H. Jiang, Y. Jiang, Z. Sun, and Q. Wu, "Effect of the excavation clearance of an under-crossing shield tunnel on existing shield tunnels," Tunnelling and Underground Space Technology, vol. 78, pp. 245-258, 2018.

[25] R. K. Rowe, K. Y. Lo, and G. J. Kack, "A method of estimating surface settlement above tunnels constructed in soft ground," Canadian Geotechnical Journal, vol. 20, no. 1, pp. 11-22, 1983.

[26] G. Mollon, D. Dias, and A. H. Soubra, "Probabilistic analyses of tunneling-induced ground movements," Acta Geotechnica, vol. 8, no. 2, pp. 181-199, 2013.

[27] C. Zhang, J. Yu, and M. Huang, "Effects of tunnelling on existing pipelines in layered soils," Computers and Geotechnics, vol. 43, pp. 12-25, 2012. 